\title{
A Prática Docente na Educação Básica e as relações com a Educação CTS
}

\section{Teaching Practice in Basic Education and it's relation to CTS Education}

\author{
Daiane Kist (dayanekist@gmail.com) \\ Mestranda em Ensino de Ciências. Universidade Federal da Fronteira Sul (UFFS) \\ Sinara München (sinara.munchen@uffs.edu.br) \\ Doutora em Educação em Ciências. Docente na Universidade Federal da Fronteira Sul (UFFS)
}

\begin{abstract}
Resumo: Este artigo tem o objetivo de identificar e analisar como as pesquisas sobre Educação CTS propostas em teses e dissertações conduziram o desenvolvimento das práticas docentes. A abordagem metodológica é qualitativa, composta pela investigação de dissertações e teses da Biblioteca Digital de Teses e Dissertações (BDTD) do IBICT (Instituto Brasileiro de Informação em Ciência e Tecnologias), iniciando-se com uma busca temática das palavras-chaves "formação de professores", "CTS" e "prática". A análise foi realizada de acordo com as etapas da Análise Textual Discursiva. Este artigo estabelece discussões sobre a primeira categoria intermediária que emergiu durante a análise das teses e dissertações, denominada 'desenvolvimento das práticas docentes na educação básica'. As reflexões realizadas no decorrer desta pesquisa apontam para o que precisa ser repensado e quais as possibilidades para a qualificação do processo de ensino e aprendizagem. Por fim, concluímos que a inserção dos pressupostos da educação CTS na prática docente ocorre de forma parcial, fato que demonstra a necessidade de serem criados programas de formação continuada voltados às interrelações da educação CTS.
\end{abstract}

Palavras-chaves: Ensino de Ciências; Formação inicial e continuada; Reflexão sobre a prática.

\begin{abstract}
The objective of this article is to identify and to analyze how the researches about CTS education presented in theses and dissertation guided the development of teaching practices. The methodology approach is qualitative, composed by investigation in dissertation and theses from Biblioteca Digital de Teses e Dissertações (BDTD) do IBICT (Instituto Brasileiro de Informação em Ciência e Tecnologias). We started looking for theme keywords: teachers' formation, CTS, and practice. The analyses were accomplished according to Textual Discourse Analysis steps. This article discusses about the first intermediate step that arise during the theses and dissertation analysis, called development of teaching practices in Basic Education. The reflections accomplished during this research show what is necessary to rethink and which possibilities are shown for the qualification in this process of teaching and learning. Finally, we conclude that the insertion of the assumptions of CTS in education in teaching practice happens in a partial way. These demonstrate the need to create programs for continuing formation related to the inter relation in CTS education.
\end{abstract}

Recebido em: 18/01/2021

Aceito em: 24/02/2021 
Keywords: Science Teaching; Initial and continuing Formation; Reflections about the practice.

\section{INTRODUÇÃO}

A educação CTS é vista como um dos meios para formarmos cidadãos atuantes em sociedade, pois visa à formação voltada para o senso crítico que se preocupa com as modificações que ocorrem ao seu redor, entendendo, questionando e interferindo ativamente nesse processo. Strieder e Kawamura (2017) destacam que existe preocupação relacionada à busca pelo desenvolvimento de relações e percepções entre o conhecimento científico escolar e o contexto do aluno. Esta preocupação com a falta de motivação e a baixa aprendizagem dos alunos em Ciências passou a fazer parte das discussões sobre a melhoria do ensino, nas últimas décadas do século XX.

Atualmente estamos inseridos em uma sociedade altamente tecnológica, que a cada dia inova e aperfeiçoa aparelhos e tecnologias que divulgam facilitar a vida de todos. A ideia da educação CTS dentro da sala de aula objetiva preparar os alunos para discernirem a respeito destas tecnologias, sendo capazes de compreender a necessidade de tal equipamento ou inovação, atuando perante esta sociedade, e não apenas consumindo estes aparatos sem questionamentos a respeito dos benefícios e prejuízos que podem vir a ocorrer.

Ensinar Ciência neste mundo contemporâneo exige conhecimento amplo a respeito das necessidades e inovações propostas pela sociedade. Atualmente vivenciamos um contexto de forte presença da ciência e da tecnologia, demarcada pela produção de alimentos transgênicos, medicamentos, organismos geneticamente modificados, dentre outros produtos que necessitam da aplicação contínua da ciência e da tecnologia, essa evolução da sociedade exige cidadãos críticos e atuantes na busca de soluções para os problemas que surgem no decorrer dos anos (SCHEID, 2018).

Abordar a educação CTS em sala de aula exige repensar o processo de formação e principalmente de atuação dos professores. Segundo Auler (2002, p. 45), os professores "sentem-se presos a estruturas curriculares mais tradicionais, expressas por diferentes agentes escolares: materiais didáticos, exames externos, expectativa de pais e alunos, 
orientações institucionais", o que vem dificultando o processo de modificação das práticas docentes.

Firme (2020) ressalta pontos importantes sobre a educação CTS, evidenciando que o professor deve estar apto para discutir a respeito das novas tecnologias como sendo um conhecimento específico que possui características próprias e se desenvolve com a ciência. O professor ainda deve caracterizar a ciência como atividade humana, que busca transformar a realidade, no sentido de contribuir para o desenvolvimento de uma consciência tecnológica pelos estudantes, através de relações que são estabelecidas com a sociedade em diferentes níveis (FIRME, 2020).

Consequentemente, os pressupostos da educação CTS vão muito além de uma simples adaptação curricular para melhorar o entendimento dos alunos sobre determinado assunto (SANTOS, 2026). A abordagem CTS não visa unicamente a dar exemplos do cotidiano com intuito de explicar de uma forma mais simples determinado conteúdo. A educação CTS parte dos acontecimentos do cotidiano para expor, demonstrar e averiguar, articuladamente ao conteúdo de sala de aula, como aquele fenômeno ocorreu, instigando os alunos a construir a consciência científico-tecnológica e as suas relações com a sociedade em seus diferentes níveis.

De acordo com Capelo e Pedrosa (2011) incluir as inter-relações da educação CTS no processos de ensino e aprendizagem de ciências tem como objetivo enfatizar a "necessidade de todos os alunos, enquanto cidadãos, serem capazes de, na sua vida prática, ponderar argumentos e tomar decisões, atendendo a avanços científicostecnológicos atuais" (CAPELO; PEDROSA, 2011, p.447). Em concordância com o exposto acima podemos destacar que pra se trabalhar com os pressupostos da educação CTS, o cotidiano dos alunos deve passar a incorporar os temas abordados em sala de aula, de forma a construir vínculos entre os acontecimentos do cotidiano e os conhecimentos científicos trabalhados nas aulas.

Santos (2012, p. 50) caracteriza a educação CTS dentro do ensino de ciências "pelo seu foco nas inter-relações entre os três elementos da tríade, e pela interseção de propósitos entre o ensino de ciências, a educação tecnológica e a educação para a cidadania no sentido da participação na sociedade". Reforçando, dessa forma, que, para o trabalho com a educação CTS ser efetivo, é de extrema necessidade que os conceitos sejam trabalhados de forma interdisciplinar e que evidenciem as relações existentes 
entre a tríade CTS, tendo como um dos pontos de partida a abordagem temática calcada no cotidiano dos estudantes.

A prática docente voltada para a educação CTS está, há tempos, prevista nos documentos que norteiam a educação. As Orientações Curriculares para o Ensino Médio (OCNEM) (Brasil, 2006) inferem que trabalhar com os pressupostos da educação CTS objetiva construir competência que auxiliam na formação do pensamento crítico, afirmando que o enfoque CTS pode contribuir na construção de competências como a formação de atitudes críticas perante os acontecimentos sociais que envolvam conhecimentos científicos e tecnológicos.

Em conformidade com o exposto nas OCNEM, destacamos que a inserção dos pressupostos da educação CTS na prática docente "intenciona-se que, de posse do conhecimento científico relacionado com o tema em debate, o aluno tenha condições de melhor intervir em sua realidade" (HALMENSCHLAGER, 2014, p. 179). Da mesma forma que, de acordo com a autora supracitada, entende-se que "a abordagem de temas socialmente relevantes, que contemplem as relações CTS, configura uma alternativa curricular para a significação do conteúdo escolar” (HALMENSCHLAGER, 2014, p.179).

Para que a abordagem em questão seja considerada como integrante da educação CTS, deve apresentar algumas características. Segundo Santos (2012), estas caraterísticas incluem a necessidade de estabelecer discussões de cunho multidisciplinar, explorando as temáticas do ponto de vista econômico, social, político, cultural, ambiental e ético. Estas discussões demandam uma série de atividades que devem ser realizadas dentro do espaço escolar, o que, muitas vezes, tem como limitação o tempo de desenvolvimento.

De acordo com Strieder e Kawamura (2017), a educação CTS é guiada por distintos propósitos educacionais, que giram em torno de três grandes grupos com o objetivo de promover uma educação científica que visa a contribuir para o desenvolvimento da sociedade. Os três grandes grupos se resumem em: “(i) percepções entre o conhecimento científico escolar e o contexto do aluno; (ii) questionamentos sobre situações sociais relacionadas à cidadania e (iii) compromissos sociais diante de problemas ainda não estabelecidos" (STRIEDER; KAWAMURA, 2017, p.42). 
Considerando todos os prós da educação CTS aqui mencionados, recaímos no ponto de partida de todo o processo educacional: a formação dos docentes. O tipo de formação, seja ela inicial ou continuada, exerce importantes influências na prática docente, o que pode acarretar no direcionamento do processo de ensino e a aprendizagem dos estudantes.

Ao refletirmos sobre a educação CTS estar presente na formação dos docentes, deparamo-nos com expressivas diferenças, afinal, muitos professores atuantes em sala de aula foram formados quando as diretrizes norteadoras da educação ainda não mencionavam os pressupostos das inter-relações da educação CTS, que, segundo Santos e Auler (2011), foram incorporados no cenário educacional brasileiro apenas em meados de 2010, como pesquisas relacionadas à educação que, até o momento, não estão sendo desenvolvidas ativamente nas práticas pedagógicas. A preocupação, nesse sentido, é se estes docentes participam de programas de formação continuada que embasam tais pressupostos.

A preocupação, anteriormente mencionada, recai diretamente na prática docente, afinal o professor tende a desenvolver em sala de aula aquilo que ele aprendeu em seu processo de formação enquanto estudante de licenciatura e com os modelos de professores com quem teve contato na graduação. Um dos pontos de partida para o desenvolvimento de práticas voltadas para a educação CTS é a formação, seja inicial ou continuada, destes profissionais que atuam em sala de aula.

Os programas de formação continuada são de extrema importância para atualizar os docentes sobre as modificações ocorridas, tanto nas orientações curriculares, quanto nas tecnologias e propostas de reorganização existentes. Marcolan e Maldaner (2015) descrevem as importantes relações estabelecidas em programas de formação continuada, relatando que:

compreende-se que o processo de formação continuada, já no contexto de atuação profissional, é de suma importância para atender às necessidades de formação sentidas pelos professores e às demandas da educação. A formação continuada é uma formação sempre e cada vez mais necessária devido às mudanças que ocorrem nas orientações curriculares e nas necessidades socioculturais (MARCOLAN; MALDANER, 2015, p. 214).

Em seguida, pensando no desenvolvimento da prática docente voltada para a educação CTS, surge o questionamento sobre como a educação CTS está sendo trabalhada em sala de aula, como e se estão sendo desenvolvidas práticas docentes Recebido em: 18/01/2021 
voltadas para os pressupostos da educação CTS e de que forma o professor foi ou está se preparando para trabalhar com tais abordagens.

\section{METODOLOGIA}

A pesquisa conta com material descritivo, portanto adquire cunho qualitativo, segundo as ideias de Lüdke e André (2013). Para a análise dos dados utilizamos a Análise Textual Discursiva como metodologia, pois, segundo Moraes e Galiazzi (2016), a ATD "não pretende testar hipóteses para comprová-las ou refutá-las ao final da pesquisa; a intenção é a compreensão, a reconstrução de conhecimentos existentes sobre os temas investigados" (MORAES; GALIAZZI, 2016, p. 33).

O corpus de análise foi constituído por teses e dissertações, partindo de pesquisa bibliográfica realizada na Biblioteca Digital de Teses e Dissertações (BDTD) do IBICT (Instituto Brasileiro de Informação em Ciência e Tecnologias), na qual foram selecionadas pesquisas que apresentavam o desenvolvimento de práticas docentes ligadas aos pressupostos da educação CTS. Como critério de seleção, buscamos as palavras-chaves: CTS, prática docente e formação continuada. A partir das palavraschave, foram encontradas 88 pesquisas que se dividem em 67 dissertações e 21 teses. Cabe ressaltar que coletamos todos os resultados disponíveis na BDTD que contemplassem os termos de busca, não estipulando um período inicial, colhendo todas as pesquisas datadas até abril de 2020 .

$\mathrm{Na}$ análise preliminar realizamos a leitura dos títulos, palavras-chaves e resumos das teses e dissertações, para selecionarmos as que mais se aproximavam do objetivo central da nossa pesquisa. Após, realizamos a leitura completa dos estudos, identificando nove teses e duas dissertações que fomentaram discussões sobre o desenvolvimento de práticas docentes, CTS e formação continuada. As pesquisas foram identificadas por códigos, respeitando a ordem cronológica das publicações. As dissertações foram identificadas por $\mathrm{D}$ e as teses por $\mathrm{T}$.

\section{RESULTADOS E DISCUSSÕES}


As teses e dissertações foram lidas com o propósito de iniciar a unitarização, que "implica examinar os textos em seus detalhes, fragmentando-os no sentido de produzir unidades constituintes" (MORAES; GALIAZZI, 2016, p. 33). Com a unitarização, evidenciamos 165 unidades de significados, agrupadas em 10 categorias iniciais - cinco categorias intermediárias e duas finais - que emergiram a partir das unidades de significado construídas desde o corpus de análise (MORAES; GALIAZZI, 2016).

Este trabalho estabelece discussões sobre a primeira categoria intermediária que emergiu durante a análise. A categoria é denominada 'desenvolvimento das práticas docentes na educação básica' e emergiu após a aproximação de 22 unidades de significado que descrevem diretamente as práticas docentes voltadas para a educação CTS.

A necessidade de discutir a respeito do desenvolvimento das práticas docentes deve-se à carência de desenvolvimento destas e emergiu dos excertos selecionados. De acordo com Strieder (2012), a perspectiva CTS entende que o conhecimento racional não é suficiente para resolver os problemas da realidade e que o desenvolvimento da sociedade deve ser pensado em um contexto que envolva a participação social, mas considera ainda que estas discussões dificilmente saem da teoria para serem aplicadas na prática docente.

Ainda de acordo com a autora, "é possível perceber uma preocupação com o desenvolvimento de um compromisso social, principalmente, ao defender que o enfoque CTS deve contribui para a superação da "cultura do silêncio" e para a transformação da realidade" (STRIEDER, 2012, p. 222). Ao discorrer sobre a cultura do silêncio, referimo-nos à cultura de aceitar as modificações e inovações das tecnologias sem uma preocupação crítica sobre os pontos positivos e negativos que este ato pode acarretar ao nosso contexto.

Na sequência, destacamos o excerto contido na Dissertação 1, denominada D1, que ressalta a importância da reflexão dos paradigmas quando se pretende utilizar a abordagem CTS:

a adoção da abordagem CTS de ensino de ciências na prática docente a partir do que apontamos como desejável, implica uma reflexão sobre o paradigma de tecnologia do professor e, neste sentido, destacamos a relevância de discussões epistemológicas sobre a natureza da tecnologia nos processos de formação de professores de ciências (COELHO, 2005, p. 121). 
Segundo Firme (2020), a utilização da abordagem CTS no ensino exige reflexões sobre o paradigma de tecnologia do docente que vem a ser construído durante o processo formativo do mesmo. Logo, percebe-se que, para termos reflexões referentes aos paradigmas tecnológicos, os professores precisam ser formados, inicial ou continuamente, calcados em pressupostos da educação CTS. München (2019) afirma que se torna necessário que a formação dos professores possibilite espaços de discussão e reflexão sobre abordagens que visam a superação do ensino fragmentado e limitado por conceitos, o que nos direciona às abordagens da educação CTS.

Em conformidade com o exposto, destacamos a tese (T1), ao relatar que "percebemos que a formação dos egressos caracteriza um relevante fator no que se refere ao uso das vocações do enfoque CTS em suas práticas docentes" (CORTEZ, 2018, p. 159). Este excerto vai ao encontro das ideias de München (2016), quando a autora destaca que as inter-relações CTS precisam ser problematizadas nos espaços formativos para que exerçam modificações nas práticas docentes.

Além da formação, para que o enfoque CTS seja desenvolvido no processo de ensino e aprendizagem, o professor precisa ter outro posicionamento, refletir sobre a sua formação e a sua prática, tendo em mente que deve ser um mediador em sala de aula, que orienta o aluno em sua busca pela aprendizagem autônoma e significativa. Em concordância com o exposto, D3 (SILVA, 2010, p. 69), destaca que "as concepções dos professores sobre as inter-relações CTS dizem respeito às suas próprias experiências nesse campo", o que corrobora diretamente com D6 (FERNANDES, 2016, p.17), ao frisar que "os professores tiveram que refletir sobre suas práticas fundamentadas nos pressupostos teóricos-metodológicos, além de lidarem com as inseguranças, as incertezas e os obstáculos no contexto escolar”.

D9 destaca que, para desenvolver a postura crítica e reflexiva nos alunos, "os docentes devem assumir a postura crítica seja em relação ao conteúdo exposto em sala de aula ou sobre a sua própria prática" (BATISTA, 2019, p. 13). Ainda em relação aos docentes, D6 ressalta que "os educadores são os mediadores do conhecimento, os condutores do processo de aprendizagem dos alunos e, por isso, devem estar em constante aprimoramento de sua prática pedagógica” (FERNANDES, 2016, p. 60).

Sobre o desenvolvimento das práticas pedagógicas em sala de aula, destacamos o excerto contido em $\mathrm{T} 2$, quando o autor descreve a respeito da importância de o 
professor entender os objetivos que os alunos externam sobre o próprio processo de ensino e aprendizagem, "o conhecimento que possui a respeito deles, da sua situação, seus objetivos, suas expectativas. Essa é uma condição básica necessária para alcançar a contextualização do ato educativo" (RODRIGUEZ, 2018, p. 127).

Também se percebe a necessidade lançada para os questionamentos dos estudantes sobre o mundo que os cerca e, a partir disso, objetiva-se promover mecanismos de trabalho que englobem estas questões, promovendo um debate concreto e construtivo que engrandece ambos os lados envolvidos. Sobre a relevância dos questionamentos, $\mathrm{T} 2$ ressalta que:

não são apenas os questionamentos dos estudantes que adquirem importância, também se tornam primordiais aqueles que faz o professor sobre os temas e processos desenvolvidos, juntamente com os que faz a si mesmo a respeito de sua própria prática (RODRIGUEZ, 2018, p. 105).

Na sequência, ressaltamos a importância em questionar a própria prática, pois, quando o professor reflete a respeito do seu campo de atuação, passa a questionar a importância de trabalhar determinados conteúdos. Segundo T2, "a partir de dito conhecimento, é possível o surgimento de novas ideias e possibilidades de intervenção, bem como de estratégias didáticas e projetos acadêmicos" (RODRIGUEZ, 2018, p. 127).

Ao refletir sobre a própria prática, o professor abre novos caminhos e promove reflexões sobre o processo de ensino. A respeito da reflexão sobre a própria prática, destacamos o excerto de Garrido e Brzezinski (2008), quando descrevem a riqueza contida no ato de refletir sobre suas ações em sala de aula:

a "pesquisa na prática" ou "reflexão sobre a reflexão na ação" em que os professores envolvidos ressignificam suas práticas e propõem novas estratégias de ação, torna o próprio processo de intervenção objeto de pesquisa. A natureza processual marca a investigação reflexiva. $\mathrm{O}$ professorpesquisador, ao intervir, muda a realidade que estuda. E ele próprio também se modifica: passa a ter outra compreensão da situação. Por sua vez, os outros agentes também mudam a realidade, como resposta às inovações introduzidas. Cria-se uma espiral de mudança que precisa ser investigada, para poder ser aperfeiçoada (GARRIDO; BRZEZINSKI, 2008, p. 155).

Em concordância com o excerto contido em T2, acima citado, destacamos a importância de a prática docente ser trabalhada de forma interdisciplinar, facilitando ao aluno o entendimento de que as disciplinas escolares são interligadas, que estas podem ser trabalhadas de forma articulada umas com as outras para promover $\mathrm{o}$ 
desenvolvimento da consciência crítica. Em concordância com o exposto, destacamos T2 (RODRIGUEZ, 2018, p. 135), ao manifestar que "é necessário deixar de lado a cultura individualista e promover o trabalho cooperativo entre professores".

$\mathrm{O}$ ato de investigar a própria prática docente viabiliza a melhoria no processo de ensino por promover reflexões a respeito dos problemas diariamente vivenciados em uma sala de aula. Ponte (2008) cita algumas razões para se promover a investigação da própria prática, enfatizando que primeiramente ela contribui para que os problemas sejam melhor resolvidos, da mesma forma que afirma a ocorrência do aprimoramento do desenvolvimento profissional e cultural, que reflete no reconhecimento da sociedade em geral.

A reflexão da própria prática docente ainda auxilia na proposição de uma ciência menos neutra, pois, quando o professor reflete e pesquisa a respeito do seu fazer docente, adquire postura crítica e reconhece, por mais que seja difícil, que a modificação da prática docente se faz necessária. Gil-Pérez, no ano de 1995, já esboçava indícios da necessária modificação da prática docente, ao discorrer que:

é claro que esta mudança didática não é fácil. Não é apenas questão de uma tomada de consciência específica, mas sim exige uma atenção contínua até tornar natural o fato de colocar em questão o que na atividade docente parece óbvio, sua revisão à luz dos resultados da pesquisa educativa (GIL-PÉREZ, 1995, p. 39).

Outro ponto importante, anteriormente mencionado, foi a necessidade de desenvolver o processo de ensino com foco na interdisciplinaridade. Ao citarmos interdisciplinaridade, consequentemente nos direcionamos a pensar no trabalho em conjunto, desenvolvido por grupos de uma ou de diferentes áreas de atuação. Nesse sentido, T2 destaca que:

a análise realizada permitiu a reflexão a respeito dos diferentes envolvimentos e contribuições formativos decorrentes da construção e aplicação de sequências com enfoque CTS, assinalando aspectos fundamentais para a prática docente como: o planejamento de atividades de forma coerente e contextualizada, a pesquisa, o trabalho colaborativo, a formação sócio-política, a responsabilidade social e o desenvolvimento do pensamento crítico (RODRIGUEZ, 2018, p. 150).

Ainda, ao mencionarmos o desenvolvimento do pensamento crítico, direcionamos a atenção para a participação do indivíduo em sociedade, sendo capaz de promover a cidadania. Os cidadãos devem desenvolver-se criticamente, de modo que sejam capazes 
de atuar modificando a realidade em que vivem. Santos e Schnetzler (2010), destacam que:

considerando que cidadania se refere à participação dos indivíduos na sociedade, torna-se evidente que, pra o cidadão efetivar sua participação comunitária, é necessário que ele disponha de informações que estão diretamente vinculadas aos problemas socias que afetam o cidadão, os quais exigem um posicionamento quanto ao encaminhamento de suas soluções (SANTOS; SCHNETZLER, 2010, p.46).

Os excertos acima citados externam fatos sobre o desenvolvimento das práticas docentes da mesma forma que ressaltam a importância de o professor promover reflexões, tanto sobre os questionamentos dos alunos, como também sobre seu campo de atuação. As reflexões podem apontar para o que precisa ser repensado no ensino e quais as possibilidades para a qualificação do processo de ensino e aprendizagem, promovendo um olhar crítico dos estudantes e professores para as relações entre ciência e sociedade.

\section{CONCLUSÃO}

Em síntese, os excertos introduzem a necessidade do desenvolvimento das práticas docentes e da formação inicial e/ou continuada dos professores estar calcada nos pressupostos da educação CTS. Quando o docente vem de uma formação que teve contato com determinadas abordagens, ele terá a possibilidade de trabalhar estas abordagens em sala de aula com mais clareza.

Logo, as práticas voltadas para a educação calcada nos pressupostos da educação CTS visam a formar cidadãos que tenham consciência científico-tecnológica desenvolvida para atuar, opinar e modificar o meio em que vivem. A utilização dos acontecimentos do cotidiano age como a fonte de dados mais utilizada nesta abordagem, servindo como ponto inicial de discussões e interpelações que irão direcionar o ensino e a aprendizagem para os conteúdos que fazem parte do currículo da escola.

Outro ponto que surgiu no decorrer das discussões foi a necessidade de refletir sobre a própria prática docente. Esta reflexão possibilita que o professor balize os pontos que devem ser revistos e modificados em sua atuação, para que assim a ciência 
ensinada na sala de aula adquira características que a distanciem da neutralidade comumente utilizada.

O ato de refletir sobre a própria prática ainda viabiliza a inserção dos pressupostos da educação CTS em sala de aula, da mesma forma que auxilia na promoção do trabalho calcado na interdisciplinaridade, por externar a ideia de que a ciência deve ser trabalhada de forma articulada dentro da área. Ainda transparece a necessidade de reorganização curricular, a qual também tem por objetivo inserir distintas abordagens no processo de ensino e aprendizagem, que, por sua vez, recaem sobre a discussão inicial aqui apresentada, que se refere à formação de cidadãos críticos capazes de atuar em sociedade, modificando e melhorando o contexto em que vivem.

Em suma, deparamo-nos com o planejamento curricular das escolas, tendo este a função de gerenciar o processo de ensino e aprendizagem, que, como citado anteriormente, muitas vezes permanece estagnado por anos sem ser modificado com a mesma incidência que ocorrem as alterações da ciência, da tecnologia e da sociedade. Com base nisso, é necessário sugerir e debater sobre a reorganização curricular com o objetivo de incluir a educação CTS nas abordagens em sala de aula.

As pesquisas analisadas indicam que o desenvolvimento de práticas baseadas nos pressupostos da educação CTS ocorre parcialmente. O desenvolvimento das práticas surge dos questionamentos dos professores e também das necessidades expostas pelos alunos sobre acontecimentos que os cercam. Na maioria das vezes percebe-se a utilização de exemplos do cotidiano com o ideal de simplificar determinada explicação, fato que se distancia do ideal demonstrado pelos pressupostos da educação CTS.

Este trabalho evidenciou aspectos significativos sobre a inserção dos pressupostos da educação CTS como prática docente no processo de ensino e de aprendizagem de ciências. A inserção destas práticas voltadas para a educação CTS visam a contribuir com o processo de ensino e aprendizagem, pois tem como meta formar a consciência crítica e tecnológica nos estudantes, preparando-os para reconhecer e agir ativamente nas transformações da ciência, da tecnologia e da sociedade.

Portanto, cabe ressaltar que a prática docente é responsável por externar como foi a formação inicial ou está sendo a formação continuada de cada professor. $O$ ato de refletir sobre a própria prática influencia diretamente no desenvolvimento desta em sala de aula, externando os aspectos que precisam ser modificados para suprir as Recebido em: 18/01/2021

Aceito em: 24/02/2021 
Edição Especial: I SSAPEC - Simpósio Sul-Americano de Pesquisa em Ensino de Ciências

ISSN: 2595- $4520 \quad$ Vol. 4, n. 3. 2021

necessidades da formação inicial dos professores, da mesma forma que a formação continuada, voltada para a educação CTS, contribui ativamente para que modificações relevantes ocorram no métodos utilizados pelos docentes.

\section{REFERÊNCIAS}

AULER, Décio. Interações entre ciência-tecnologia-sociedade no contexto da formação de professores de ciências. Orientador: Demétrio Delizoicov. 2002. 257 p. Tese (Doutorado em Educação Científica e Tecnológica) - Universidade Federal de Santa Catarina, Florianópolis, 2002. Disponível em:

https://repositorio.ufsc.br/handle/123456789/82610. Acesso em: 16 maio 2020.

BATISTA, Karine de Cássia Prado. Influência do Discurso Docente na Construção da Visão de Ciência dos Estudantes Alinhada aos Objetivos do Enfoque CTS.

Orientadora: Alice Assis. 2019. 108 p. Dissertação (Mestrado em Educação em Ciências) - Universidade Federal de Itajubá, Itajubá, 2019. Disponível em:

https://repositorio.unifei.edu.br/xmlui/handle/123456789/2098. Acesso em: 29 abr. 2020.

BRASIL. Secretaria de Educação Básica. Ministério da Educação. Orientações Curriculares para o Ensino Médio - Ciências da Natureza, Matemática e suas Tecnologias. Brasília, 2006. Disponível em:

http://portal.mec.gov.br/component/content/article?id=13558. Acesso em: 20 dez. 2020.

CAPELO, Ana; PEDROSA, Maria Arminda. Formação inicial de professores de ciências, problemas atuais e percursos investigativos. In: SANTOS, Wildson Luiz Pereira dos; AULER, Décio (orgs). CTS e a educação científica: desafios, tendências e resultados de pesquisas. Brasília: Editora Universidade de Brasília, 2011. p. 439461.

\section{COELHO, Juliana Cardoso. A Chuva Ácida na Perspectiva de Tema Social: Um}

Estudo com Professores de Química em Criciúma (SC). Orientador: Carlos Alberto Marques. 2005. 174 p. Dissertação (Mestrado em Educação Científica e Tecnológica) Universidade Federal de Santa Catarina, Florianópolis, 2005. Disponível em: http://repositorio.ufsc.br/handle/123456789/101912. Acesso em: 29 abr. 2020. 
Edição Especial: I SSAPEC - Simpósio Sul-Americano de Pesquisa em Ensino de Ciências

ISSN: 2595- $4520 \quad$ Vol. 4, n. 3. 2021

CORTEZ, Jucelino. A Abordagem CTS no Contexto da Formação e da Atuação

Dos Professores da Área de Ciências da Natureza. Orientador: José Claudio Del

Pino. 2018. 129 p. Tese (Doutorado em Educação em Ciências) - Universidade Federal do Rio Grande do Sul, Porto Alegre, 2018. Disponível em:

https://lume.ufrgs.br/handle/10183/180187. Acesso em: 29 abr. 2020.

FERNANDES, Roseane Freitas. Educação CTS e Interdisciplinaridade:

Perspectivas para Professores do Ensino Médio. Orientadora: Roseline Beatriz

Strieder. 2016. 193 p. Dissertação (Mestrado em Ensino de Ciências) - Universidade de

Brasília, Brasília, 2016. Disponível em: http://repositorio.unb.br/handle/10482/22052.

Acesso em: 29 abr. 2020.

FIRME, Ruth do Nascimento. Abordagem Ciência-Tecnologia-Sociedade no Ensino de Ciências: de qual tecnologia estamos falando desde esta perspectiva em nossa prática docente? Góndola, Enseanza y Aprendizaje de las Ciencias, v. 15, p. 65-82, 2020. Disponível em: https://revistas.udistrital.edu.co/index.php/GDLA/article/view/14300. Acesso em: 15 dez. 2020.

GARRIDO, Elsa; BRZEZINSKI, Iria. A Reflexão e Investigação da Própria Prática na Formação Inicial e Continuada: contribuição das dissertações e teses no período 1997 2002. Revista Diálogo e Educação, Curitiba, v. 8, n. 23, p. 153-171, jan./abr. 2008. Disponível em: https://periodicos.pucpr.br/index.php/dialogoeducacional/article/viewFile/4003/3919. Acesso em: 05 jan. 2021.

GIL-PÉREZ, Daniel. Formação de professores de ciências: tendências e inovações. 2ed. São Paulo: Cortez, 1995.

HALMENSCHLAGER, Karine Raquiel. Abordagem de temas em Ciências da Natureza no Ensino Médio: implicações na prática e na formação docente. Orientador: Demétrio Delizoicov. 2014. 273 p. Tese (Doutorado em Educação Científica e Tecnológica) - Universidade Federal de Santa Catarina, Florianópolis, 2014. Disponível em: https://repositorio.ufsc.br/handle/123456789/94336. Acesso em: 20 dez. 2020.

LÜDKE, Menga; ANDRE, Marli E. D. A. Pesquisa em educação: abordagens qualitativas. $2^{\mathrm{a}}$ ed. Rio de Janeiro: E. P. U., 2013, p.128.

MARCOLAN, Simone Gobi; MALDANER, Otavio Aloisio. Espaços de Formação Continuada de Professores em Escolas Pequenas e Isoladas: Uma Lacuna a Ser Preenchida. Química nova na Escola - São Paulo. Vol. 37, № 3, p. 214-223, 2015. Disponível em: http://qnesc.sbq.org.br/online/qnesc37_3/09-EQF-05-14. Acesso em: 03 jan. 2021. 
MORAES, Roque; GALIAZZI, Maria do Carmo. Análise Textual Discursiva. $3^{\mathrm{a}} \mathrm{ed}$. Ijuí: Ed. Unijuí, 2016.

MÜNCHEN, Sinara. A Inserção da Perspectiva Ciência-Tecnologia-Sociedade na Formação Inicial de Professores de Química: O Movimento Ciência-TecnologiaSociedade e sua Inserção no Contexto Educacional. Orientador: Martha Bohrer Adaime. 2016. 148 p. Tese (Doutorado em Educação em Ciências) - Universidade Federal de Santa Maria., Santa Maria, 2016. Disponível em:

http://repositorio.ufsm.br/handle/1/3557. Acesso em: 20 mar. 2020.

MÜNCHEN, Sinara. A Inserção da Perspectiva Ciência-Tecnologia-Sociedade na Formação Inicial de Professores de Química. Revista Insignare Scientia, v. 2, n. 2, p. 416-434, 2019. Disponível em: https://periodicos.uffs.edu.br/index.php/RIS/article/view/10999/7338. Acesso em: 11 fev. 2021.

PONTE, João Pedro da. Investigar a nossa própria prática: uma estratégia de formação e de construção do conhecimento profissional. Revistas da Universidade de Granada. v. 02, nº 04. 2008, p. 153-180. Disponível em: https://revistaseug.ugr.es/index.php/pna/issue/view/472. Acesso em: 06 jan. 2021.

RODRÍGUEZ, Andrei Steveen Moreno. Enfoque Ciência, Tecnologia E Sociedade (CTS): Contribuições para a Profissionalização Docente. Orientador: José Claudio Del Pino. 2018. 212 p. Tese (Doutorado em Educação em Ciências) - Universidade Federal do Rio Grande do Sul, Porto Alegre, 2018. Disponível em: http://hdl.handle.net/10183/180977. Acesso em: 29 abr. 2020.

SANTOS, Rosemar Ayres. Busca de uma participação social para além da avaliação de impactos da ciência- tecnologia na sociedade: sinalizações de práticas educativas CTS. Orientador: Décio Auler. 2016, 205 p. Tese (Doutorado em Educação) - Universidade Federal de Santa Maria, Santa Maria, 2016. Disponível em: https://repositorio.ufsm.br/handle/1/3513. Acesso em: 01 jul. 2020.

SANTOS, Wildson Luiz Pereira dos; AULER, Décio. CTS e a educação científica: desafios, tendências e resultados de pesquisas. Brasília: Editora Universidade de Brasília, 2011.

SANTOS, Wildson Luiz Pereira dos; SCHNETZLER, Roseli Pacheco. Educação em química: compromisso com a cidadania. Ijuí: Editora Unijuí, 2010.

SANTOS, Wildson Luiz Pereira dos. Educação CTS e Cidadania: Confluências e Diferenças. AMAZÔNIA - Revista de Educação em Ciências e Matemáticas. v.9 $\mathrm{n}^{\circ}$ 17. 2012, p.49-62. Disponível em:

https://periodicos.ufpa.br/index.php/revistaamazonia/article/view/1647/2077. Acesso em: 02 jan. 2021.

SILVA, Karolina Martins Almeida. Abordagem CTS no Ensino Médio: Um Estudo de Caso da Prática Pedagógica de Professores de Biologia. Orientador: Leandro Gonçalves Oliveira. 2010. 161 p. Dissertação (Mestrado em Educação em Ciências e 
Edição Especial: I SSAPEC - Simpósio Sul-Americano de Pesquisa em Ensino de Ciências

matemática) - Universidade Federal de Goiás, Goiânia, 2010. Disponível em:

http://repositorio.bc.ufg.br/tede/handle/tde/401. Acesso em: 29 abr. 2020.

SCHEID, Neusa Maria John. História da ciência na educação científica e tecnológica: contribuições e desafios. Revista Brasileira Ensino Científico e Tecnológico. Ponta Grossa, v. 11, n. 2, p. 443-458, 2018. Disponível em:

https://periodicos.utfpr.edu.br/rbect/article/view/8452. Acesso em; 20 nov. 2020.

STRIEDER, Roseline Beatriz. Abordagem CTS na Educação Científica no Brasil:

Sentidos e perspectivas. Tese (Doutorado em Ensino de Ciências) - Universidade de

São Paulo. São Paulo, p. 283. 2012. Disponível em:

https://www.teses.usp.br/teses/disponiveis/81/81131/tde-13062012-112417/pt-br.php.

Acesso em: 24 dez. 2020.

STRIEDER, Roseline Beatriz; KAWAMURA, Maria Regina Dubeux. Educação CTS:

Parâmetros e Propósitos Brasileiros. ALEXANDRIA: Revista de Educação em

Ciência e Tecnologia. Florianópolis, v. 10, n. 1, p. 27-56, maio. 2017. Disponível em: https://periodicos.ufsc.br/index.php/alexandria/article/view/1982-5153.2017v10n1p27. Acesso em: 02 Jan. 2021. 